\title{
The Impact of Social Support on Infertility-Related Stress: A Study in the Vietnamese Context
}

\author{
Truong Quang Lam ${ }^{1}$, Trinh Thi Linh ${ }^{1}$, Luong Bich Thuy ${ }^{2}$ \\ ${ }^{1}$ Faculty of Psychology, University of Social Sciences and Humanities, Vietnam National University (VNU-Hanoi), Hanoi, \\ Vietnam \\ ${ }^{2}$ Faculty of Sociology, University of Social Sciences and Humanities, Vietnam National University (VNU-Hanoi), Hanoi, Vietnam \\ Email: lamtq.psy@gmail.com, anhlinh_huong@yahoo.com, luongbichthuy@gmail.com
}

How to cite this paper: Lam, T. Q., Linh, T. T., \& Thuy, L. B. (2021). The Impact of Social Support on Infertility-Related Stress: A Study in the Vietnamese Context. Open Journal of Social Sciences, 9, 259-273. https://doi.org/10.4236/jss.2021.912017

Received: November 10, 2021

Accepted: December 11, 2021

Published: December 14, 2021

Copyright $\odot 2021$ by author(s) and Scientific Research Publishing Inc. This work is licensed under the Creative Commons Attribution International License (CC BY 4.0).

http://creativecommons.org/licenses/by/4.0/ (c) (i) Open Access

\begin{abstract}
This study aimed to evaluate the prediction of social support on infertility-related stress in the socio-cultural context in Vietnam. Participants were selected by convenient sampling method, including 997 primary infertility people in 3 regions of Vietnam namely North, Central, and South. Two scales were used, the Multidimensional Scale of Perceived Social Support (MSPSS) and the Fertility Problem Inventory (FPI), to measure social support and infertility-related stress. Research results show that infertile people in Vietnam report that they receive the most support from their family, followed by support from significant others and friends. The results of multivariate regression analysis of three aspects of social support with only family support predicted an impact on reducing infertility-related stress on the entire participant and with infertile women. In infertile men, significant other support was a predictor of increased infertility-related stress in this group. Our research also shows the importance of education for people with infertility. Discussions from a psychological and cultural perspective further clarify these findings in the Vietnamese context.
\end{abstract}

\section{Keywords}

Social Support, Infertility, Stress, Vietnamese

\section{Introduction}

Producing, raising and educating children is one of the basic functions of the family. Entering married life, welcoming the birth of a child is the wish of all couples, however, that seemingly simple thing becomes very difficult for those 
who are infertile. Infertility is a medical defined as a reproductive related disease which causes the failure to a clinical pregnancy after 12 months or more among couples with regular unprotected sexual intercourse (Zegers-Hochschild et al., 2009). Many studies have shown that infertility creates psychological trauma for people, and childlessness leads to suffering and depression, as well as stigma and ostracism (Cui, 2010; Chachamovich et al., 2010). Newton et al. (1999) identify five key aspects of infertility-related stress: social concern, sexual concern, relationship concern, rejection of childfree lifestyle, and need for parenthood. Compared with patients with other medical conditions, the psychological symptoms associated with infertility and their treatment are similar to those in patients with cancer, hypertension, and cardiac rehabilitation (Lawson et al., 2014; Domar et al., 1993). Across many cultures, individuals perceive childlessness as a sign of impairment, disability, and impairment (Dyer et al., 2005; Cousineau \& Domar, 2007; Ombelet et al., 2008). Besides, in countries like China, having many children and grandchildren can be considered as one of the leading standards of happiness in many families; having children is a guarantee of economic maintenance and care for people in old age (Lee et al., 2001; Culley et al., 2004; Lau et al., 2008; Loke et al., 2011). Most young Chinese men and women feel a cultural compulsion to have children in order to continue the lineage.

In a highly communal society like Vietnam, family members are bound together by biological as well as social and psychological relationships (Mesquita, 2001), marriage is seen as a family union (Triandis, 1994), and the roles of family members are largely determined by cultural factors (McGoldrick et al., 2005). Thus, individuals are usually logically expected to marry and have children. Research by Wiersema et al. (2006) showed that infertile couples in South Vietnam are under great psychological pressure. Couples without children after a year of marriage will be asked the reason for not having children, which causes pain and feelings of pressure for them. Other studies have shown that infertility often leads to psychological problems, such as prejudice, pain, disappointment, self-pity, low self-esteem, low-spirit (Nguyen, 2011a), anxiety, distress, and hopelessness (Nguyen \& Nguyen, 2017; Truong, 2020), and depression (Vo et al., 2019; Le \& Nguyen., 2020). Among men, the highest levels of stress were reported in the need for parenthood, followed by rejection of a childfree lifestyle (Truong, et al., 2021). In both men and women, infertility is associated with severe stress, affecting sexual function, quality of life, and depression (Ho et al., 2017; Le et al., 2015). Findings from research have shown that the negative psychological aspects of infertile people in Vietnam have been and are going through, so they need social support to overcome their situation.

Overall, social support plays an important role, helping a person adapt to life's crises and lead a healthy life. It acts as a mental cleanser (Crockett et al., 2007; Hayden et al., 2007), enabling individuals to overcome mental stress by feeling belonging to one or more groups. Evidence for the association between social support and adjustment to life stressors has been shown in numerous studies (Uchino, 2006; Decker, 2007; Casale \& Wild, 2012). In publications related to the 
topic of infertility, the authors have identified a range of psychosocial variables that are considered risk or protective factors for infertility stress, such as such as personality traits, cognition, social support, coping, and perception of control. With regard to protective factors, many studies report that greater social support from the partner and social network is correlated with lower levels of stress related to infertility (Gourounti et al., 2010). In both fertile and infertile people, the more support they received from their spouse, the greater their marital satisfaction (Abbey et al., 1995). Thus, marital satisfaction is also an indicator of mate support, which may be protective against stress in general as well as stress related to infertility in particular (Chochovski et al., 2013; Gourounti et al., 2010). In another study, low family support predicted treatment termination after 1 year for both men and women (Vassard et al., 2012). Adequate awareness of social support can be effective in coping with psychological stress and distress in infertile women. Abbey et al. (1992) showed that satisfaction with social support network was negatively correlated with stress related to infertility. Slade et al. (2007) also reported that social support was negatively associated with infertility stress, as well as anxiety and depression. Furthermore, the authors reported that marital relationship satisfaction was associated with reduced symptoms of depression and anxiety in infertile women. Research by Ying et al. (2015) allows to conclude that for both men and women, support from a partner is negatively correlated with stress caused by infertility. A significant number of studies have also found that social support can facilitate successful coping with infertility problems and cognitive adaptation in the face of infertility crises (Martins et al., 2011; Scrignaro et al., 2011). However, when compared by gender, social support is negatively correlated with stress in infertile women while in men it is not (Sreshthaputra et al., 2008). Low levels of social support from family and partner are correlated with infertility stress in women, whereas for men, this correlation is only observed with support from a partner (Martins et al., 2014).

While most studies argued that social support is considered a protective factor for the mental health of infertile people, some studies also point to the opposite direction of this support. For example, in a qualitative study, Ying et al. (2015) found that for some participants, receiving social support from their parents contributed to a reduction in their stress. In contrast, some reported that social support from their parents was an additional stressor because they felt guilty for adding to the burden on their parents. Research results Wiersema et al. (2006) also pointed out that psychological support is not part of the treatment for infertility in South Vietnam. Infertile couples face questions about childless marriage from those around them. Family intervention is also seen as a negative pressure on them. Women who have failed treatment feel devalued when they receive support from their husband's family (Truong, 2020). Patel et al. (2018) have shown that distress is three times greater in infertile women whose family members are deeply involved.

In Vietnam, several studies have shown a positive effect of social support on some patient groups. In particular, in postpartum women, support from family 
and other supports has helped reduce psychological disturbances and improve self-esteem (Tran et al., 2016). For the elderly, resources from families and social organizations have contributed to improving and enhancing self-care for the elderly's mental health, reducing stress, and increasing their ability to cope with stress (Hoang \& Trinh., 2019). For cancer patients, the routine care of the family and regular updates of the medical staff's information both play an important role in their palliative care (Tran \& Le, 2019). For middle-aged women, social support resources play an important and motivating role in self-care activities among middle-aged women (Luong \& Ha, 2021). For infertile people in Vietnam, studies also report family support, but it does not appear to be effective for infertility problems (Wiersema et al., 2006; Truong, 2020).

\section{Research Aim}

Although studies in Vietnam all acknowledge the psychological difficulties faced by infertile people, research on the impact of social support on them is still limited. Therefore, the objective of the article is to: 1 ) investigate the level of social support that infertile people in Vietnam receive; 2) examine the impact of social support on infertility-related stress in Vietnamese infertile people. Based on the results, recommendations regarding appropriate supports and interventions for infertile people will be made for the Vietnamese cultural context, which is the basis for.

\section{Method}

\subsection{Procedure and Samples}

The study was approved by the Universsity of Social Sciences and Humanities, Vietnam National University (VNU), where the research team was affiliated with, and the three hospitals in the north (Hanoi) and central (Da Nang), and south of Vietnam (Ho Chi Minh City), and two fertility clinics, where participants were recruited. In this survey, a questionnaire based on standard scales was selected. The scale is translated from English to Vietnamese. Then, an independent consultant conducted a back translation from Vietnamese to English to validate the translation.

A total of 997 Vietnamese people (602 female) with primary infertility diagnosis, who have never become pregnant before, were recruited from three hospitals in the northern, central and the south regions of Vietnam, using convenient sampling. The research team collaborated with medical experts from three hospitals to invite people who had been diagnosed with primary infertility to participate in the study. We have clearly explained the purpose and process of the study, the information obtained is completely anonymous and is for research purposes only. Participation is voluntary, and participants may withdraw from the study at any time. The participants consented through written consent and orally. A total of 997 participants answered the questionnaire at the hospital. The questionnaire response time lasted from 30 to 35 minutes, and the participants 
received a small gift.

\subsection{Measures}

Infertility-related stress. Infertility-related stress in Vietnamese people was measured with Fertility Problem Inventory (FPI; Newton et al., 1999). FPI consists of 46 items covering five key aspects of intertility-related stress, including: 1) Social concern (e.g., It doesn't bother me when P $m$ asked questions about children); 2) Sexual concern (e.g., I find I ve lost enjoyment of sex because of the fertility problem); 3) Relationship concern (e.g., My partner doesn't understand the way the fertility problem affects me); 4) Rejection of childfree lifestyle (e.g., Couples without a child are just as happy as those with children); and 5) Need for parenthood (e.g., For me, being a parent is a more important goal than having a satisfying career). For each item, participants chose one response out of six choices ( 1 = strongly agree; 2 = moderately agree; $3=$ slightly agree; $4=$ slightly disagree; $5=$ moderately disagree; $6=$ strongly disagree). Global stress was computed by summarizing the points of all 46 items. Cronbach's alpha coefficients of the global stress were 0.84 .

Social support. The Multidimensional Scale of Perceived Social Support (MSPSS, Zimet et al., 1988) was used to measure the level of perceived social support from family (e.g., My family really tries to help me); friends (e.g., I can talk about my problems with my friends); and significant other, who were not family and friends (e.g., There is a special person with whom I can share my joys and sorrows). Twelve-item ratings were set on a 7-point Likert-type scale ranging from very strongly disagree (1) to very strongly agree (7). Overall, MSPSS has demonstrated good plausibility and reliability in previous studies (Cankaya, 2002; Cevik et al., 2011). In our study, Cronbach's alpha coefficients of three subscales were $0.83,0.81$, and 0.88 respectively, and of the global social support was 0.89 .

\subsection{Statistical Analyses}

The data of the study were processed using SPSS 22.0 software. In addition to descriptive statistics, multivariate regressions were applied to evaluate the impact of infertile people's perceived social support on the overall stress associated with infertility. Multivariate regressions were performed on the total sample, women, and men respectively. Two different models were used for each group, including Model 1 with only key predictors of types of social support, and Model 2 with added covariates (age, education, years of marriage, years of pregnancy expectation, and years of diagnosed infertility).

\section{Results}

\section{Sample characteristics}

The main demographic characteristics of participants are presented in the Table 1. All participants in the study, 602 female and 395 male, aged 20 and above, 
Table 1. Descriptive characteristics of the study sample $(\mathrm{N}=997)$.

\begin{tabular}{|c|c|c|c|}
\hline Variables & $\begin{array}{c}\%(\mathrm{n}) \text { or } \\
{[\mathrm{Min}-\mathrm{Max}]}\end{array}$ & $\begin{array}{c}\text { Mean } \\
(S D)\end{array}$ & $\begin{array}{c}\text { Cronbach's } \\
\text { alpha }\end{array}$ \\
\hline \multicolumn{4}{|c|}{ Demographic characteristics/Covariates } \\
\hline Age & {$[20-53]$} & $32(4.78)$ & \\
\hline \multicolumn{4}{|l|}{ Gender } \\
\hline Female & $60(602)$ & & \\
\hline Male & 40 (395) & & \\
\hline \multicolumn{4}{|l|}{ Education } \\
\hline High school and lower & $38.82(387)$ & & \\
\hline College and higher & $61.18(610)$ & & \\
\hline Years of marriage & {$[1-22]$} & $5.10(3.60)$ & \\
\hline Years of pregnancy expectation & {$[0.25-21]$} & $4.51(3.02)$ & \\
\hline Years of diagnosed infertility & {$[0-21]$} & $3.84(2.90)$ & \\
\hline Infertility-related stress & {$[1.71-4.98]$} & $3.41(0.47)$ & 0.841 \\
\hline Social support & {$[1.00-7.00]$} & $4.96(1.09)$ & 0.893 \\
\hline Family & {$[1.00-7.00]$} & $5.59(1.10)$ & 0.836 \\
\hline Friend & {$[1.00-7.00]$} & $4.63(1.34)$ & 0.815 \\
\hline Significant other & {$[1.00-7.00]$} & $4.71(1.54)$ & 0.887 \\
\hline
\end{tabular}

were married for at least a year. Their average years of pregnancy expectation were $5.10(S D=3.60)$, which was close to their average years of diagnosed infertility $(\mathrm{M}=3.84, S D=3.02)$. Regarding education, there were 387 (38.82\%) high school and lower, 610 (61.18\%) college and higher.

Participants reported an average score of infertility-related stress at 3.41 ( $S D=$ $0.47)$, while social support averaged at $4.96(S D=1.09)$. The mean scores of family support, friend support, and significant other support were $5.59(S D=1.10)$, $4.63(S D=1.34)$, and $4.71(S D=1.54)$ respectively.

\section{Predictions of social support for infertility-related stress}

Table 2 shows that, in model 1, when considering the effects of 3 sources of social support simultaneously, the results only show the predictive power of family support on overall stress related to infertility $(\beta=-0.12)$. An interesting thing that we noticed in model 2 , when adding demographic variables, the results indicate that 2 predictors of global stress related to infertility are family support $(\beta=-0.15)$ and education level $(\beta=-0.17)$. Thus, if family support is increased and higher education is obtained, the stress related to infertility will tend to decrease. Even so, these two models only explain $1.6 \%$ and $4.3 \%$ of the variability of the data obtained.

In order to assess the potential impact of social support on the infertility stress faced by women and men, multivariate regression analysis for each group of subjects was performed (Table 3(a) \& Table 3(b)). 
T. Q. Lam et al.

Table 2. Multivariate regression model predictive of social support for infertility-related stress.

\begin{tabular}{ccc}
\hline & \multicolumn{2}{c}{ Standardized Coefficients $(\beta)$} \\
\cline { 2 - 3 } Social support & Model 1 & Model 2 \\
Family & $-0.12^{\star *}$ & $-0.15^{\star *}$ \\
Friends & -0.06 & -0.017 \\
Significant other & 0.07 & 0.061 \\
Covariates & & -0.06 \\
Age & - & $-0.17^{\star *}$ \\
Education (College and higher) & - & -0.04 \\
Years of marriage & - & 0.04 \\
Years of pregnancy expectation & - & 0.04 \\
Years of diagnosed infertility & - & $0.053^{\star}$ \\
$\mathrm{R}^{2}$ & $0.019^{\star}$ & $0.043^{\star}$ \\
Adjusted $\mathrm{R}^{2}$ & $0.016^{\star}$ & \\
\hline 0.01. & & \\
\hline
\end{tabular}

${ }^{\star} p<0.05 ;{ }^{* *} p<0.01$.

Table 3. (a) Multivariable regression model predicts the effect of social support on infertility-related stress in women; (b) Multivariable regression model predicts the effect of social support on infertility-related stress in men.

(a)

\begin{tabular}{|c|c|c|}
\hline & \multicolumn{2}{|c|}{ Standardized Coefficients $(\beta)$} \\
\hline & Model 1 & Model 2 \\
\hline \multicolumn{3}{|l|}{ Social support } \\
\hline Family & $-0.14^{\star *}$ & $-0.15^{\star \star}$ \\
\hline Friends & -0.04 & 0.02 \\
\hline Significant other & 0.01 & -0.05 \\
\hline \multicolumn{3}{|l|}{ Covariates } \\
\hline Age & - & -0.05 \\
\hline Education (College and higher) & - & $-0.18^{\star \star}$ \\
\hline Years of marriage & - & -0.05 \\
\hline Years of pregnancy expectation & - & 0.06 \\
\hline Years of diagnosed infertility & - & 0.03 \\
\hline $\mathrm{R}^{2}$ & $0.026^{*}$ & $0.064^{*}$ \\
\hline Adjusted $\mathrm{R}^{2}$ & $0.021^{\star}$ & $0.047^{\star}$ \\
\hline$p<0.05 ;{ }^{* *} p<0.01$ & & \\
\hline
\end{tabular}


(b)

\begin{tabular}{ccc}
\hline & \multicolumn{2}{c}{ Standardized Coefficients $(\beta)$} \\
\cline { 2 - 3 } Model 1 & Model 2 \\
\hline Family & & \\
Friends & -0.08 & -0.13 \\
Significant other & -0.10 & -0.05 \\
Covariates & $0.14^{*}$ & $0.19^{* *}$ \\
Age & & \\
Education (College and higher) & - & -0.03 \\
Years of marriage & - & $-0.14^{*}$ \\
Years of pregnancy expectation & - & -0.04 \\
Years of diagnosed infertility & - & 0.03 \\
$\mathrm{R}^{2}$ & - & 0.03 \\
Adjusted $\mathrm{R}^{2}$ & $0.021^{*}$ & $0.060^{*}$ \\
& 0.013 & $0.033^{*}$ \\
\hline
\end{tabular}

${ }^{\star} p<0.05 ;{ }^{* *} p<0.01$.

In Table 3(a), for women, model 1 shows that family support is the only variable that predicts the opposite variation in infertility-related stress $(\beta=-0.14)$. Combining the demographic variables in model 2, the two significant predictors of overall stress related to infertility are family support $(\beta=-0.15)$ and education level $(\beta=-0.18)$. Thus, when they receive support from their family and have a higher level of education, women tend to be less stressed about their infertility situation.

In contrast, in men (Table 3(b)), the model 1 and model 2 data only recorded the predictive power of the supporting variable from significant other $(\beta=0.14)$. In other words, support from a significant other is a factor that increases stress in infertile men. However, higher education was also found to be a factor in reducing the overall stress associated with male infertility $(\beta=-0.14)$.

\section{Discussion}

This study examines the impact of social support resources on 997 Vietnamese diagnosed with infertility in the North, Central and South. The limitations of this study are that it is a convenient random sample, the number of subjects is not equal between men and women, and there is a lack of qualitative research to indicate the mechanism of the impact of social support on infertility-related stress. Despite the limitations, the results of the study provide insight into the actual impact of social support resources on infertile people in the Vietnamese context.

Research results show that infertile people report receiving social support 
from all sources such as family, friends, significant other. In which, the participants reported that they received the most support from family, followed by support from significant others and from friends. This result is also consistent with what Martins et al. (2011) pointed out in their study. Accordingly, in addition to the support received from the spouse, the subjects also noted the high support from the family. Perhaps this trend is explainable because like all other individuals in society, the family has always been considered as the subsystem closest to each person. This is even much truer for infertile people in Vietnam. Because, compared to the general income of Vietnamese people, infertility treatment requires resources not only of the individual but in many cases, the resources of the whole family. Moreover, in Eastern societies like Vietnam, having a baby is not only a reproductive function but also a waiting, an expectation, a "norm" of a normal family. Therefore, "finding children" is not only a "battle" of infertile people but also involves most of their family members.

When considering all three sources of social support at the same time, recognizing only family support as a predictor of reducing infertility-related stress in the study subjects, again for see the importance of families in helping infertile individuals cope with their difficulties. Accordingly, if family members are the ones who understand and share with infertile people, their ability to overcome difficulties during infertility treatment will be easier. Our results have similarities with some previous studies have shown (Shiu-Neng \& Pei-Fan, 2008; Mahajan et al., 2009). Accordingly, although family and friends are often considered "useless" in efforts to treat infertility, family support is of great significance in helping individuals and couples cope with infertility-related stress. Of course, it is also important to be aware of the appropriateness of family support. Because over-supporting may not produce the desired results, for example, it creates pressure on couples (Wiersema et al., 2006). Patel et al. (2018) has shown that distress is three times greater in infertile women whose family members are overly involved and have unrealistic expectations from treatment cycles compared with women who did not disclose treatment-related details to their families. Women who were accompanied by a family member during treatment sessions had twice as much distress as women who were accompanied by only their husbands during treatment sessions.

Our study also points to the importance of Vietnamese infertile people's education level on infertility-related stress. As shown in the results, those with higher education predicted a reduction in stress related to infertility. This finding is consistent with several studies that have shown that education level has been shown to be a strong predictor of seeking medical help in both infertile men and women (Moreau et al., 2010; Swift \& Liu, 2014), reducing infertility-related stress (Truong et al., 2021). Highly educated infertile people can protect themselves from mental health problems (Li et al., 2018), while those with less education face more difficulties in this infertility treatment (Drosdzol \& Skrzypulec, 2008). 
One interesting thing that we noticed from the results of this study was that for men, social support did not predict a positive effect on infertility stress. Even when receiving support from a significant other, the stress related to infertility tends to increase. In other words, the social support they received did not relieve them of their inner tension. This can be explained by traditional cultural factors, Vietnam is also a Confucian country, men value family and clan, having children to continue the lineage is very important to them (Wiersema et al., 2006; Truong et al., 2021). On the other hand, from a cultural perspective, if men are affected by infertility, childlessness and sexual dysfunction are often thought to be synonymous (Throsby \& Gill, 2004; Keylor \& Apfel, 2010; cited by Wischmann \& Thorn, 2013). So, along with receiving attention from social support sources, it is inevitable that opinions will put men under pressure. Therefore, it is understood that as a consequence of receiving a discriminatory comment (Daniluk, 2001), it should not reduce the stress associated with infertility, even make infertile men more stressed when receiving support from someone who has a significant other.

Meanwhile, women are often waited and expected to give birth after getting married. Getting married without children is still a stereotype that is assigned to women. Many families are even deeply involved in couples' infertility treatment (Wiersema et al., 2006; Nguyen, 2011b; Truong, 2020). As we have just shown above, Patel et al. (2018) have noted that this very deep involvement has increased stress and suffering in women during infertility treatment. In many cases, women look to infertility groups on social media to share their feelings and experiences (Sormunen et al., 2021). The results of our study show that, although the forecast results are not profound, receiving support from the family predicts a positive influence, helping infertile women to be less stressed. Unlike some previous studies, which did not allow to record a statistically significant difference between infertile men and women in perceived social support (Slade et al., 2007; Sreshthaputra et al., 2008, cited by Ying et al., 2015), our study shows the role of family factors in infertile women. This is consistent with the socio-cultural reality of Vietnamese people when children are a valued value. Besides, seeking the support of reproductive technology requires a very high cost compared to the income of Vietnamese people. Therefore, in the state of infertility, if women receive sharing from family, support during treatment, as well as financial support... women will feel more secure and less pressured. Accordingly, their stress will also be reduced.

\section{Conclusion}

In summary, in the Vietnamese cultural context, infertile people also report that the sources of social support they receive are diverse. However, we found that the impact of social support on infertility stress was not profound. Our research results suggest that building a psychological intervention model is essential for infertile people in Vietnam. Besides, it is also necessary to improve understand- 
ing for the family and the people in general, so that they can understand infertility, so that social support will really help infertile people to reduce stress in their situation.

\section{Acknowledgements}

This research is funded by Vietnam National Foundation for Science and Technology Development (NAFOSTED) under grant number 501.01-2019.03.

\section{Conflicts of Interest}

The authors declare no conflicts of interest regarding the publication of this paper.

\section{References}

Abbey, A., Andrews, F. M., \& Halman, L. J. (1992). Infertility and Subjective Well-Being: The Mediating Roles of Self-Esteem, Internal Control, and Interpersonal Conflict. Journal of Marriage and Family, 54, 408-417. https://doi.org/10.2307/353072

Abbey, A., Andrews, F., \& Halman, L. (1995). Provision and Receipt of Social Support and Disregard: What Is Their Impact on the Marital Life Quality of Infertile and Fertile Couples? Journal of Personality and Social Psychology, 68, 455-469. https://doi.org/10.1037/0022-3514.68.3.455

Cankaya, B. (2002). Psychosocial Factors, Maladaptive Cognitive Schemas, and Depression in Young Adults: An Integration. Thesis of Master of Science. Blacksburg, Virginia.

Casale M., \& Wild, L. (2012). The Relationship between Social Support and the Health of HIV-Positive Caregivers of Children: A Review of the Empirical Literature. Vulnerable Child Youth Studies, 7, 260-282. https://doi.org/10.1080/17450128.2012.668232

Cevik, Y., Kelleci, M., Golbasi, Z., Caykoylu, A., \& Das, M. (2011). Epidemiological Survey and MSPSS Scores of 260 Suicide Attempters Presenting to Two Emergency Departments in Turkey. Hong Kong Journal of Emergency Medicine, 18, 412-420.

Chachamovich, J. L. R., Chachamovich, E., Ezer, H., Cordova, F. P., Fleck, M. M. P., Knauth, D. R., \& Passos, E. P. (2010). Psychological Distress as Predictor of Quality of Life in Men Experiencing Infertility: A Cross-Sectional Survey. Reproductive Health, 7 , 3. https://doi.org/10.1186/1742-4755-7-3

Chochovski, J., Moss, S. A., \& Charman, D. P. (2013). Recovery after Unsuccessful in Vitro Fertilization: The Complex Role of Resilience and Marital Relationships. Journal of Psychosomatic Obstetrics \& Gynecology, 34, 122-128. https://doi.org/10.3109/0167482X.2013.829034

Cousineau, T. M., \& Domar, A. D. (2007). Psychological Impact of Infertility. Best Practice \& Research Clinical Obstetrics and Gynaecology, 21, 293-308.

https://doi.org/10.1016/j.bpobgyn.2006.12.003

Crockett, L. J., Iturbide, M. I., Torres Stone, R. A., McGinley, M., Raffaelli, M., \& Carlo, G. (2007). Acculturative Stress, Social Support, and Coping: Relations to Psychological Adjustment among Mexican American College Students. Cultural Diversity and Ethnic Minority Psychology, 13, 347-355. https://doi.org/10.1037/1099-9809.13.4.347

Cui, W. (2010). Mother or Nothing: The Agony of Infertility. Bulletin of the World Health Organization, 88, 881-882. https://doi.org/10.2471/BLT.10.011210 
Culley, L., Rapport, F., Katbamna, S., Johnson, M., \& Hudson, N. (2004). A Study of the Provision of Infertility Services to South Asian Communities. De Montfort University.

Daniluk, J. C. (2001). "If We Had It to Do Over Again...": Couples' Reflections on Their Experiences of Infertility Treatments. The Family Journal, 9, 122-133. https://doi.org/10.1177/1066480701092006

Decker, C. L. (2007). Social Support and Adolescent Cancer Survivors: A Review of the Literature. Psycho-Oncology, 16, 1-11. https://doi.org/10.1002/pon.1073

Domar, A. D., Zuttermeister, P. C., \& Friedman, R. (1993). The Psychological Impact of Infertility: A Comparison with Patients with Other Medical Conditions. Journal of Psychosomatic Obstetrics and Gynaecology, 14, 45-52.

Drosdzol, A., \& Skrzypulec, V. (2008). Quality of Life and Sexual Functioning of Polish Infertile Couples. The European Journal of Contraception \& Reproductive Health Care, 13, 271-281. https://doi.org/10.1080/13625180802049187

Dyer, S. J., Abrahams, N., Mokoena, N. E., Lombard, C. J., \& van der Spuy, Z. M. (2005). Psychological Distress among Women Suffering from Couple Infertility in South Africa: A Quantitative Assessment. Human Reproduction, 20, 1938-1943.

https://doi.org/10.1093/humrep/deh845

Gourounti, K., Anagnostopoulos, F., \& Vaslamatzis, G. (2010). Psychosocial Predictors of Infertility Related Stress: A Review. Current Women's Health Reviews, 6, 318-331. https://doi.org/10.2174/157340410793362159

Hayden, B. Y., Parikh, P. C., Deaner, R. O., \& Platt, M. L. (2007). Economic Principles Motivating Social Attention in Humans. Proceedings. Biological Sciences, 22, 1751-1756. https://doi.org/10.1098/rspb.2007.0368

Ho, T. T. T., Le, M. T., Le, Dinh D., Truong, Q. V., \& Cao, N. T. (2017). Sexual Function in Infertile Couples: Is There a Reciprocal Relationship? The Journal of Obstetrics and Gynecology, 15, 162-167.

Hoang, M. L., \& Trinh, T. L. (2019). Mental Health Self-Care Activities of Vietnamese Elderly in the Community. Hanoi National University Publishing House.

Lau, J. T. F., Wang, Q., Cheng, Y., Kim, J. H., Yang, X., \& Yi, T. H. (2008). Infertility-Related Perceptions and Responses and Their Associations with Quality of Life among Rural Chinese Infertile Couples. Journal of Sex \& Marital Therapy, 34, 248-267. https://doi.org/10.1080/00926230701866117

Lawson, A. K., Klock, S. C., Pavone, M. E., Hirshfeld-Cytron, J., Smith, K. N., \& Kazer, R. R. (2014). Prospective Study of Depression and Anxiety in Female Fertility Preservation and Infertility Patients. Fertility and Sterility, 102, 1377-1384. https://doi.org/10.1016/j.fertnstert.2014.07.765

Le, M. T., \& Nguyen, T. N. (2020). Study on Psychological Disorders in Infertile Patients Using Beck Depression Inventory (BDI). The Journal of Obstetrics and Gynecology, 18, 67-73. https://doi.org/10.46755/vjog.2020.2.1118

Le, M. T., Truong, M. D., Nguyen, T. D. T., \& Cao, N. T. (2015). Study on Quality of Life of Infertile Couples Undergoing IVF Treatment. The Journal of Obstetrics and Gynecology, 13, 115-120. https://doi.org/10.46755/vjog.2015.3.907

Lee, T. Y., Sun, G. H., \& Chao, S. C. (2001). The Effect of an Infertility Diagnosis on the Distress, Marital and Sexual Satisfaction between Husbands and Wives in Taiwan. Human Reproduction, 16, 1762-1767. https://doi.org/10.1093/humrep/16.8.1762

Li, X., Wang, K., Huo, Y., \& Zhou, M. (2018). The Effect of Infertility-Related Stress on Chinese Infertile Females' Mental Health: The Moderating Role of Marital Adjustment. PsyCh Journal, 8, 232-239. https://doi.org/10.1002/pchj.255 
Loke, A. Y., Yu, P.-L., \& Hayter, M. (2011). Experiences of Sub-Fertility among Chinese Couples in Hong Kong: A Qualitative Study. Journal of Clinical Nursing, 21, 504-512. https://doi.org/10.1111/j.1365-2702.2010.03632.x

Luong, T., \& Ha, N. (2021). Impact of Supportive Resources on Middle-Aged Women's Self-Care Activities: A Study in The Vietnamese Context. Asian Social Work Journal, 6, 25-32. https://doi.org/10.47405/aswj.v6i5.189

Mahajan, N. N., Turnbull, D. A., Davies, M. J., Jindal, U. N., Briggs, N. E., \& Taplin, J. E. (2009). Adjustment to Infertility: The Role of Intrapersonal and Interpersonal Resources/Vulnerabilities. Human Reproduction, 24, 906-912.

https://doi.org/10.1093/humrep/den462

Martins, M. V., Peterson, B. D., Almeida, V. M., \& Costa, M. E. (2011). Direct and Indirect Effects of Perceived Social Support on Women's Infertility-Related Stress. Human Reproduction, 26, 2113-2121. https://doi.org/10.1093/humrep/der157

Martins, M. V., Peterson, B. D., Almeida, V., Mesquita-Guimaraes, J., \& Costa, M. E. (2014). Dyadic Dynamics of Perceived Social Support in Couples Facing Infertility. Human Reproduction, 29, 83-89. https://doi.org/10.1093/humrep/det403

McGoldrick, M., Giordano, J., \& Garcia-Preto, N. (2005). Ethnicity and Family Therapy. Guilford Press.

Mesquita, B. (2001). Emotions in Collectivist and Individualist Contexts. Journal of Personality and Social Psychology, 80, 68-74. https://doi.org/10.1037/0022-3514.80.1.68

Moreau, C., Bouyer, J., Ducot, B., Spira, A., \& Slama, R. (2010). When Do Involuntarily Infertile Couples Choose to Seek Medical Help? Fertility and Sterility, 93, 737-744. https://doi.org/10.1016/j.fertnstert.2008.10.011

Newton, C. R., Sherrard, W., \& Glavac, I. (1999). The Fertility Problem Inventory: Measuring Perceived Infertility-Related Stress. Fertility and Sterility, 72, 54-62. https://doi.org/10.1016/S0015-0282(99)00164-8

Nguyen, D. H. N., \& Nguyen. D. H. G. (2017). Mental Health Care Needs in Infertile People (Case Study at Department of Reproductive Support, A. Thai Nguyen Hospital). In Proceedings of International Conference The first Southeast Asia Regional Conference of Psychology: "Human Well-Being and Sustainable Development" (Vol. 2, pp. 70-77). Vietnam National Universiy Press.

Nguyen, T. H. P. (2011a). Trauma in Women Suffering from Infertility. Vietnam Journal of Family and Gender Studies, 1, 68-80.

Nguyen, T. H. P. (2011b). Social Attitudes on Infertility: Women's Situation and Response. In Proceedings of International Conference: 20 years of Faculty of Sociology Achievements and Challenges (pp. 350-358). Vietnam National University Press.

Ombelet, W., Cooke, I., Dyer, S., Serour, G., \& Devroey, P. (2008). Infertility and the Provision of Infertility Medical Services in Developing Countries. Human Reproduction Update, 14, 605-621. https://doi.org/10.1093/humupd/dmn042

Patel, A. S., Leong, J. Y., \& Ramasamy, R. (2018). Prediction of Male Infertility by the World Health Organization Laboratory Manual for Assessment of Semen Analysis: A Systematic Review. Arab Journal of Urology, 16, 96-102.

https://doi.org/10.1016/j.aju.2017.10.005

Scrignaro, M., Barni, S., \& Magrin, M. E. (2011). The Combined Contribution of Social Support and Coping Strategies in Predicting Post-Traumatic Growth: A Longitudinal Study on Cancer Patients. Psycho-Oncology, 20, 823-831.

https://doi.org/10.1002/pon.1782

Shiu-Neng, C., \& Pei-Fan, M. (2008). Infertile Couples' Experience of Family Stress While 
Women Are Hospitalized for Ovarian Hyperstimulation Syndrome during Infertility Treatment. Journal of Clinical Nursing, 17, 531-538.

Slade, P., O’Neill, C., Simpson, A. J., \& Lashen, H. (2007). The Relationship between Perceived Stigma, Disclosure Patterns, Support and Distress in New Attendees at an Infertility Clinic. Human Reproduction, 22, 2309-2317.

https://doi.org/10.1093/humrep/dem115

Sormunen, T., Karlgren, K., Fossum, B., Aanesen, A., \& Westerbotn, M. (2021). Focus on Infertility-Women's Experiences of Using Social Media: A Qualitative Study. Open Journal of Social Sciences, 9, 382-395. https://doi.org/10.4236/jss.2021.95020

Sreshthaputra, O., Sreshthaputra, R. A., \& Vutyavanich, T. (2008). Gender Differences in Infertility-Related Stress and the Relationship between Stress and Social Support in Thai Infertile Couples. The Journal of the Medical Association of Thailand, 91, 1769-1773.

Swift, B. E., \& Liu, K. E. (2014). The Effect of Age, Ethnicity, and Level of Education on Fertility Awareness and Duration of Infertility. Journal of Obstetrics and Gynaecology Canada, 36, 990-996. https://doi.org/10.1016/S1701-2163(15)30412-6

Tran, T. L., \& Le, T. T. (2019). Current Palliative Care Needs of Cancer Patient Being Treated in the Cancer Center-Thai Binh General Hospital in 2019. Journal of Nursing Science, 2, 13-21.

Tran, T. M. D., Bui, T. H. T., Ngo, X. D. (2016). Postpartum Women and Support Solutions. Hanoi National University Publishing House.

Triandis, H. C. (1994). Culture and Social Behavior. McGraw Hill.

Truong, Q. L. (2020). Traumas in Women Suffering from Infertility through a Case Study. Journal of Psychology, 3, 83-97.

Truong, Q. L., Luong. B. T., \& Phan, T. K. N. (2021). Stress in Men with Fertility Problems. Journal of Psychology, 3, 28-43.

Uchino, B. N. (2006). Social Support and Health: A Review of Physiological Processes Potentially Underlying Links to Disease Outcomes. Journal of Behavior and Medicine, 29, 377-387. https://doi.org/10.1007/s10865-006-9056-5

Vassard, D., Lund, R., Pinborg, A., Boivin, J., \& Schmidt, L. (2012). The Impact of Social Relations among Men and Women in Fertility Treatment on the Decision to Terminate Treatment. Human Reproduction, 27, 3502-3512. https://doi.org/10.1093/humrep/des353

Vo, T. M., Tran, Q., Le, C. V., Do, T. T., \& Le, T. M. (2019). Depression and Associated Factors among Infertile Women at Tu Du Hospital, Vietnam: A Cross-Sectional Study. International Journal of Women's Health, 11, 343-351. https://doi.org/10.2147/IJWH.S205231

Wiersema, N. J., Drukker, A. J., Dung, M., Nhu, G., Nhu, N., \& Lambalk, C. B. (2006). Consequences of Infertility in Developing Countries: Results of a Questionnaire and Interview Survey in the South of Vietnam. Journal of Translational Medicine, 4, 54. https://doi.org/10.1186/1479-5876-4-54

Wischmann, T., \& Thorn, P. (2013). (Male) Infertility: What Does It Mean to Men? New Evidence from Quantitative and Qualitative Studies. Reproductive Biomedicine Online, 27, 236-243. https://doi.org/10.1016/j.rbmo.2013.06.002

Ying, L. I., Wu, L. H., \& Loke, A. Y. (2015). Gender Differences in Experiences with and Adjustments to Infertility: A Literature Review. International Journal of Nursing Studies, 52, 1640-1652. https://doi.org/10.1016/j.ijnurstu.2015.05.004

Zegers-Hochschild, F., Adamson, G. D., de Mouzon, J., Ishihara, O., Mansour, R., Nygren, K., Vanderpoel, S. et al. (2009). International Committee for Monitoring Assisted Reproductive Technology (ICMART) and the World Health Organization (WHO) Re- 
vised Glossary of ART Terminology. Fertility and Sterility, 92, 1520-1524.

https://doi.org/10.1016/j.fertnstert.2009.09.009

Zimet, G. D., Dahlem, N. W., Zimet, S. G., \& Farley, G. K. (1988). The Multidimensional Scale of Perceived Social Support. Journal of Personality Assessment, 52, 30-41.

https://doi.org/10.1207/s15327752jpa5201_2 